\title{
O CICLO INVESTIGATIVO DE MODELAGEM MATEMÁTICA: UMA TRANSPOSIÇÃO DIDÁTICA ESCOLAR
}

\author{
THE INVESTIGATIVE CYCLE OF MATHEMATICAL MODELING: \\ A SCHOOL TEACHING TRANSPOSITION
}

\author{
GLEISON DE JESUS MARINHO SODRÉ ${ }^{1}$ \\ MANOEL LUCIVAL DA SILVA OLIVEIRA²
}

\section{RESUMO}

0 objetivo deste texto é analisar o alcance empírico do ciclo investigativo de modelagem matemática reconstruído para o estudo de problemas em contextos concretos. Para isso, foi utilizado esse ciclo construído, à luz de recursos teórico-metodológicos da teoria antropológica do didático, por pressupor que esse dispositivo didático criou condições, nem todas é claro, no sentido da transposição didática institucional para o enfrentamento do problema docente da modelagem matemática sobre como ensiná-la e, com isso, minimizar a invisibilidade dos saberes, matemáticos e não matemáticos. Resultados obtidos a partir da análise empírica com alunos do ensino médio revelam potencialidades do ciclo investigativo para aquisições de novos saberes, bem como se encaminha futura investigação.

Palavras-chave: Modelagem Matemática. Ciclo Investigativo de Modelagem Matemática. Teoria Antropológica do Didático. Saberes não matemáticos.

\section{ABSTRACT}

This text aims to analyze the empirical scope of the investigative cycle of mathematical modeling reconstructed for the study of problems in concrete contexts. For this purpose, this cycle was used in the light of theoretical and methodological resources of the anthropological theory of didactics because it presupposes that this didactic device created conditions, not all of which are clear, in the sense of institutional didactic transposition to face the teaching problem of mathematical modeling on how teach it and thereby minimize the invisibility of knowledge, mathematicians and non-mathematicians. Results obtained from the empirical analysis with high school students reveal the potential of the investigative cycle for the acquisition of new knowledge, as well as forging future research.

Keywords: Mathematical Modeling. Investigative Cycle of Mathematical Modeling. Anthropological Theory of Didactics. Non mathematical knowledge.

\footnotetext{
1 Doutor em Educação em Ciências e Matemáticas (UFPA). Escola de Aplicação da Universidade Federal do Pará. E-mail: profgleisoneaufpa@ gmail.com. Orcid: https://orcid.org/0000-0002-3993-4236

2 Doutor em Matemática (UFPA). Escola de Aplicação da Universidade Federal do Pará. E-mail: mlso@ufpa.br. Orcid: https://orcid.org/ 0000-0002-6959-6442
} 


\section{INTRODUÇÃO E O PROBLEMA DE INVESTIGAÇÃO}

A noção de Modelagem Matemática, doravante MM, no contexto da Educação Matemática, tornou-se nas últimas décadas, segundo Barquero (2020), um importante tópico de pesquisa voltado para 0 ensino e aprendizagem de objetos matemáticos em sala de aula.

Barquero (2020) destaca que, embora a MM tenha um claro avanço na pesquisa e em seu uso em sala de aula, "ainda existem muitas questões em aberto que afetam tanto a pesquisa quanto a realidade da prática, por exemplo, dificuldades de difusão a longo prazo da modelagem em sala de aula, desafios para sua avaliação, dificuldades de gerenciamento e necessidades de formação de professores"3 (CARREIRA et al., 2019) (apud BARQUERO, 2020, p. 1, tradução nossa).

Embora Barquero e Jessen (2020) destaquem a existência de diferentes modelos epistemológicos de referência sobre a MM, isto é, distintos modos de compreensões sobre a prática, a saber: 0 ciclo de MM e competências, modelos e perspectiva de MM e Teoria Antropológica do Didático, daqui em diante TAD, é preciso considerar que a noção de MM, conforme Schukajlow, Kaiser e Stillman (2018), tem se centrado, nas últimas décadas e de modo mais dominante, na perspectiva cognitivista em que assume a noção de ciclo de MM como principal ferramenta didática.

Na compreensão cognitivista, a MM é concebida em geral "como o processo da resolução de problemas do mundo real por meio de aplicação da matemática com o objetivo de compreendê-la"4 (NISS et al., 2007) (apud STILLMAN, 2019, p. 1, tradução nossa). Nesse sentido, Stillman (2019) destaca:

É mais do que aplicar a matemática, onde também começamos com um problema do mundo real, aplicamos a matemática necessária, mas depois de encontrar a solução, não pensamos mais no problema inicial, exceto para verificar se nossa resposta faz sentido (Stillman, 2004). Com a modelagem matemática, o uso da matemática é mais para entender o problema / situação do mundo real ${ }^{5}$ (STILLMAN, 2019, p. 1, tradução nossa).

0 extrato de texto revela a MM como uma prática que busca tratar de problemas do mundo real com a aplicação de objetos matemáticos necessários, sem explicitar, no entanto, que tipo de objetos matemáticos é de fato necessário, ou ainda, em que momento esses objetos matemáticos podem ser utilizados por um sujeito, isto é, em que situações é possível usar um dado objeto matemático. Nessa perspectiva, o estudo do problema inicial emerge talvez como motivação para encaminhar 0 estudo de objetos matemáticos.

É preciso considerar que, embora existam diferentes perspectivas teóricas sobre a natureza da MM (FREJD; BERGSTEN, 2018), o modo de fazer e de pensar assentado na compreensão do uso de objetos matemáticos para estudar situações do mundo real assume de maneira quase dominante 0 esquema do ciclo enquanto modelo do processo de MM (JANKVIST; NISS, 2019, STILLMAN, 2019). Então:

3 Fragmento do texto: there are still many open questions that affect both realities, research and practice, such as, for instance, difficulties of long-term diffusion of modelling in the classroom, challenges for its evaluation, difficulties of its classroom management and needs for teacher education.

4 Fragmento do texto: as real-world problem solving is the process of applying mathematics to a real-world problem with a view to understanding it.

5 Fragmento do texto: It is more than applying mathematics where we also start with a real-world prob-lem, apply the necessary mathematics, but after having found the solution we no longer think about the initial problem except to check if our answer makessense (Stillman2004). With mathematical modelling the use of mathematics is more for understanding the real-world problem/situation. 
Apesar da diversidade de representações (Perrenet \& Zwaneveld, 2012), existe um amplo consenso sobre o processo de modelagem e sua decomposição em diferentes etapas sintetizadas nas diversas versões dos ciclos de modelagem, onde modelos são construídos e usados para produzir conhecimento sobre um dado pedaço de realidade considerado como um sistema ${ }^{6}$ (BARQUERO; BOSCH; WOZNIAK, 2019, p. 2, grifos dos autores, tradução nossa).

Esquematicamente, o ciclo de MM pode ser orientado pela Figura 1.

Figura 1 - Ciclo de modelagem matemática ampliado de Blum e Leiß.

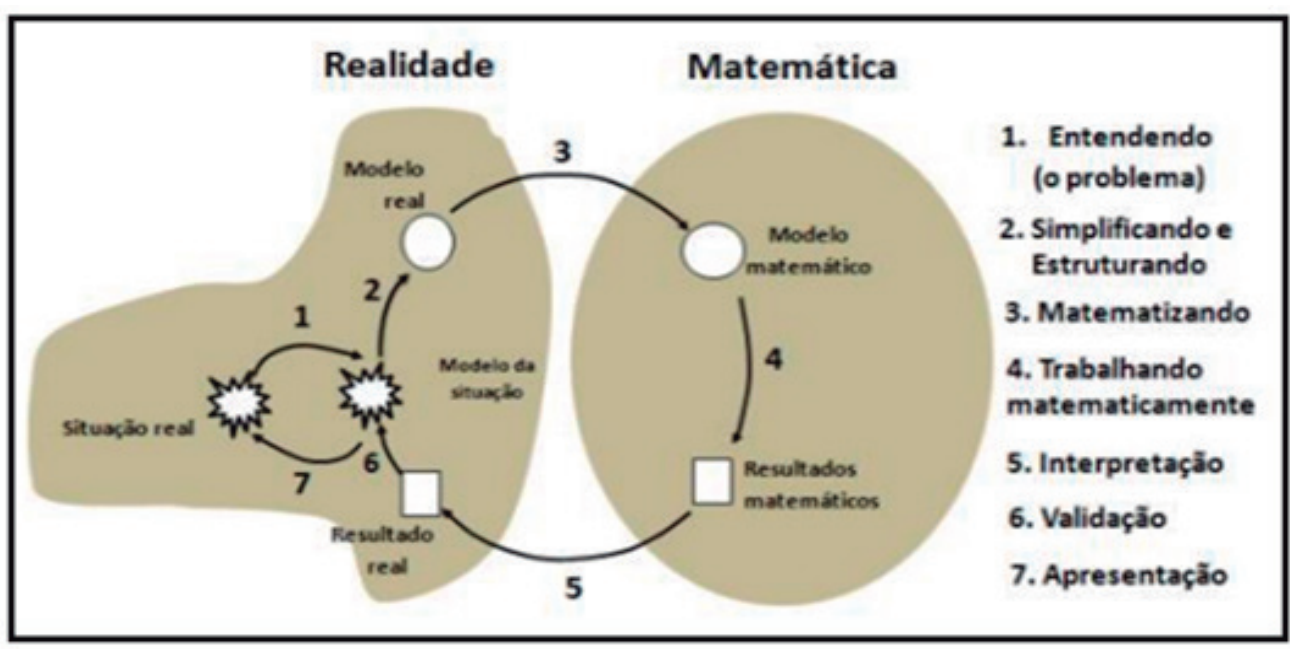

Fonte: adaptado de Blum e Leiß (2005).

Entretanto:

A maioria das pesquisas educacionais realizadas no domínio de "modelagem e aplicações" coincide no uso do "ciclo de modelagem" na descrição dos processos de modelagem, com poucas variações. No máximo, há alguns questionamentos sobre os processos cognitivos ativados em cada etapa do ciclo de modelagem ou na transição entre diferentes etapas ${ }^{7}$ (GARCIA et al. 2006, p. 231, tradução nossa).

Nesse sentido, Sodré e Guerra (2018) e Sodré (2019) também questionam o ciclo de MM para 0 ensino, em particular, pela complexidade que envolve os processos de formular, empregar, interpretar e avaliar, tomados como centrais do processo de MM (BRASIL, 2015), por se constituírem em tarefas desafiadoras para alunos e professores no estudo de problemas em contextos concretos como parece alertar Barquero, Bosch e Wozniak (2019).

6 Fragmento do texto: In spite of a diversity of representations (Perrenet \& Zwaneveld, 2012), there is a widespread consensus about the modelling process, and its decomposition in different steps synthesised in the diverse versions of modelling cycles, where models are built and used to produce knowledge about a given piece of reality considered as a system.

7 Fragmento do texto: Most of the educational research carried out in the domain of "modelling and applications" coincides in using the "modelling cycle" in the description of the modelling processes, with very few variations. At the most, there is some questioning of the cognitive processes activated in each step of the modelling cycle or in the transition between different steps. 
Sodré e Guerra (2018) propõem uma primeira versão do Ciclo Investigativo de Modelagem Matemática, daqui em diante CIMM, encaminhado de modo provisório "como metodologia de desenvolvimento e análise de modelos matemáticos de situações em contextos concretos" (SODRÉ; GUERRA, 2018, p. 253), a ser contrastado experimentalmente, portanto, suscetível de ser modificado e revisado constantemente, isto é, deve ser colocada à prova da contingência, conforme destacam Fonseca, Gascón e Lucas (2014).

0 CIMM proposto por Sodré e Guerra (2018) se orienta por meio de cinco tarefas que caracterizam uma verdadeira pesquisa (CHEVALLARD, 2013), logo, deve "ser entendido sempre como relativo e provisório, aberto a questionamento e à revisão, e pertinente na medida que seja rico para a identificação de fenômenos didáticos e formulação de problemas didáticos"8 (GARCIA et al., 2019, p. 78, tradução nossa).

Estruturalmente, o CIMM é descrito por meio das seguintes tarefas:

$\mathrm{H}_{1}$ - Investigar os modelos matemáticos existentes na escola, de modo a buscar dar visibilidade à situação em contexto;

$\mathrm{H}_{2}$ - Analisar modelos matemáticos em duplo plano, experimental e teórico, cujo processo aqui é reverso, isto é, parte-se da formulação matemática em busca da situação que essa formulação pode atender, inclusive, 0 alcance para novas situações; $\mathbf{H}_{3}$ - Avaliar os modelos matemáticos, tarefa que se dará após serem analisados os da tarefa anterior;

$\mathrm{H}_{4}$ - Desenvolver um modelo matemático a partir de sua reconstrução, considerando os modelos estudados em situações com matemáticas que serão analisadas e avaliadas; $\mathrm{H}_{5}$ - Difundir e defender 0 modelo matemático, realizado pela submissão das situações e dos modelos matemáticos associados, sujeitos à aprovação da comunidade de estudo.

0 CIMM foi desenvolvido de forma holística a partir de um problema em contexto concreto sobre financiamento de veículos com dados obtidos pelos professores em concessionárias. 0 estudo desse tipo de problema encaminhou os professores ao estudo do modelo matemático do problema de financiamento de prestações fixas.

0 caráter provisório do CIMM (SODRÉ; GUERRA, 2018, p. 259) revela que "os resultados animadores com os professores ainda são provisórios e demandam experiências empíricas com o CIMM envolvendo número maior de participantes e diversidade de situações que permitam avaliações de sua performance para futuros encaminhamentos empíricos em sala de aula".

0 CIMM até então esboçado buscou, entre outros propósitos, encaminhar possíveis respostas, apesar de parciais, ao problema docente de $\mathrm{MM}$, aqui designado por $\mathrm{P}_{0}(\mathrm{MM})$, tomado como de maior interesse nas Conferências Internacionais sobre o Ensino de Modelagem Matemática e Aplicações, ou simplesmente ICTMA, sobre como ensinar MM, que é de interesse comum tanto na abordagem cognitivista (BLUM, 2011, SCHUKAJLOW; KAISER; STILLMAN, 2018), quanto na epistemológica (BARQUERO; BOSCH; GASCÓN, 2011): $\mathrm{P}_{0}$ (MM): 0 que ensinar e como ensinar MM? (BARQUERO; BOSCH; GASCÓN, 2011, 2013).

De qualquer modo, estudar um tipo de problema em contexto concreto, como pressupõe a noção de MM, exige considerar um domínio de realidade, isto é, uma situação que, na concepção de Revuz (1971), é o primeiro processo de abstração. Essa noção é indispensável, inclusive na MM

8 Fragmentos do texto: Ser entendidos siempre como relativos y provisionales, abiertos a cuestionamien-to y revisión, y pertinentes enla medida en que seanfértiles para laidentificación de fenómenos didácti-cos y laformulación de problemas didácticos. 
escolar, por permitir talvez tratar do problema de ensino, tendo em conta que o ensino da MM, por exemplo, pode ser encaminhado a partir da elaboração de situações e de uma série de situações apropriadas para a construção do conhecimento (CHEVALLARD, 2005, p. 102, grifos do autor).

A noção de situação constitui a forte hipótese da própria definição de conhecimento matemático desde a Teoria das Situações Didática (BROUSSEAU, 1995), incluindo-se também a TAD, em que os conhecimentos são descritos em termos de situações, isto é, "um conhecimento é uma situação"9 (BOSCH; CHEVALLARD, 1999, p. 3, tradução nossa).

A MM pode ser compreendida como uma atividade humana presente em diversas instituições sociais, incluindo a escola básica, e assenta-se em estudo de situações do mundo real para o uso, estudo e construção de um modelo matemático, cuja funcionalidade nesse processo é ser um instrumento ou uma "máquina" (CHEVALLARD, 1992) para melhor permitir ao sujeito conhecer o domínio da realidade ao qual se refere o modelo matemático.

Com esse olhar, partimos do pressuposto de que as dificuldades de alunos e professores em MM decorrem da não visibilidade dos saberes em sentido amplo, de modo particular, os saberes não matemáticos condicionam e são condicionados pelos saberes matemáticos para a construção de um modelo matemático (SODRÉ; GUERRA, 2018, SODRÉ, 2019), inclusive, como nos revela Julie (2002, p. 2, tradução nossa) no seguinte extrato de texto: "A modelagem matemática não deve ser apenas um veículo para as ideias matemáticas. Permanecer nesse nível esconde o trabalho de bastidores e as complexidades envolvidas na construção de um modelo matemático"10.

Nesse sentido, embora o CIMM provisório apresentado por Sodré e Guerra (2018) revele potencialidades para formação de professores a partir da mudança de relações dos professores com a prática de MM, pressupomos que o encaminhamento do CIMM mediante ampliações propostas por Sodré (2019) pode criar condições, nem todas é claro, no sentido da transposição didática institucional (CHEVALLARD, 1999, 2005), sob certas restrições institucionais, para o estudo de situações em contexto que torne possível o ensino da MM, em particular, na instituição escolar.

Assumimos a noção de transposição didática institucional no sentido proposto por Chevallard (1999, 2005), compreendida a criação de condições sob certas restrições, que torne possível o desenvolvimento de um saber em diferentes instituições, incluindo a escola básica, por exemplo, com a possibilidade de esta instituição criar também organizações de conhecimentos inéditos para atender suas especificidades na difusão social do saber, isto é, a escola pode construir "criações didáticas" para "fins de autoconsumo" (CHEVALLARD, 2005, p. 26, grifos do autor).

A ratificação, ou mesmo a retificação de nossa hipótese nos impele a responder ao seguinte questionamento: Qual o alcance do Ciclo Investigativo de Modelagem Matemática ampliado, proposto por Sodré (2019), para o estudo de problemas em contextos concretos na escola básica?

Na esteira dessa construção, o objetivo de nossa investigação consiste no uso a partir de uma infraestrutura teórico-metodológica do CIMM ampliado, proposto por Sodré (2019), de modo a considerar seu alcance como dispositivo didático para o ensino escolar e, com isso, permitir minimizar a invisibilidade do condicionamento mútuo de saberes matemáticos e não matemáticos, de modo a assegurar nossa hipótese de investigação.

9 Fragmento do texto: une connaissance est une situation.

10 Fragmento do texto: Mathematical modelling should not only be a vehicle for these mathematical ideas. Remaining at this level conceals the "behind-the-scene" work and intricacies involved in the construc-tion of a mathematical model. 


\section{RECURSOS TEÓRICO-METODOLÓGICOS: A NOÇÃO DE ORGANIZAÇÃO PRAXEOLÓGICA COMPLEXA}

Segundo Chevallard (1999), todo produto intencional da atividade humana regularmente realizada no interior de um espaço social - que pode ser a família, a escola, por exemplos, e aqui denominados de instituições por instituírem o modo de fazer e de pensar uma prática em seu interior - pode ser descrita a partir de um modelo cuja unidade mais simples se resume pela noção de praxeologia, ou simplesmente organização praxeológica, que permite a modelagem das práticas sociais em geral.

É preciso considerar que a legitimidade institucional de uma organização praxeológica pode não estar na clareza de seus saberes teóricos que 0 integram, mas no papel funcional dos conhecimentos que podem ser capazes de permitir 0 engendramento de saberes para produzir respostas a determinadas questões de interesses de uma dada instituição.

Com esse olhar, Sodré (2019) encaminha, a partir do modelo praxeológico proposto por Chevallard (1999), que o saber das organizações praxeológicas globais apresentadas nesse modelo teórico pode ser oriundo de um saber não necessariamente teórico, mas por "saberes práticos, que se colocam em funcionamento, se aprendem, se enriquecem, sem serem entretanto utilizados, ensinados, produzidos" (CHEVALLARD, 2005, p. 154, grifos do autor, tradução nossa) de uma dada instituição, e que por sua funcionalidade em ato, encaminha à noção de Organização Praxeológica Complexa, doravante OPC (SODRÉ; GUERRA, 2018, SODRÉ, 2019).

Se assumirmos que a dificuldade do uso da MM em sala de aula, por alunos e professores, por exemplo, reside no silêncio da infraestrutura praxeológica de saberes, matemáticos e não matemáticos, minimizados de algum modo, pelo CIMM provisório apresentado por Sodré e Guerra (2018), então, a noção de MM como uma OPC (SODRÉ, 2019) pode ser paulatinamente construída a partir do CIMM ampliado e proposto por Sodré (2019), por pressupormos que este ciclo pode criar condições, embora nem todas, que permitam encaminhar a MM escolar como uma prática ensinável e, com isso, assegurar também o ensino e a aprendizagem de objetos matemáticos da escola básica.

Como resposta a esse tipo de problemática do silêncio da infraestrutura praxeológica de saberes:

Chevallard (2009) propõe a metodologia de pesquisa e desenvolvimento de organizações praxeológicas como meio de construir resposta ao problema primordial, denominada de percurso de estudo epesquisa, daqui em diante PEP. Este consiste de um processo iterativo de sistemas didáticos $S$ (Alunos, Professor, $Q_{i}$ ) instituídos para 0 estudo de questões derivadas $Q_{i}$ de uma questão geratriz $Q_{0}$, com 0 objetivo de encontrar, o que inclui construir, respostas $R_{i} \diamond$ que podem se mostrar como uma resposta desejada à questão inicial $Q_{0}$ (SODRÉ; GUERRA, 2018, p. 253).

Inspirado no PEP Orientado e proposto por Sodré (2019) a partir dos cinco gestos de uma verdadeira pesquisa (CHEVALLARD, 2013), e seguindo a intencionalidade didática do diretor de estudos pelos três gestos da MM $\boldsymbol{G}_{1}, \boldsymbol{G}_{2}$ e $\boldsymbol{G}_{3}$, isto é:

- $\mathbf{G}_{1}$ - Usar praxeologias matemáticas rotineiras da escola de modo customizado em situações com matemática escolar sobre contextos reais do cotidiano escolar e do seu entorno social;

- $\mathbf{G}_{2}$ - Estudar e, com isso aprender, modelos matemáticos, entendidos como os questionamentos sobre contextos concretos, as situações com matemática e praxeologias matemáticas customizadas associadas; 
- $\mathbf{G}_{3}$ - Criar, mesmo que se reduza apenas à customização, modelos matemáticos para novas situações com matemática em contextos a partir de analogias ou homologias com outras situações com matemática, inclusive as praxeologias customizadas associadas, sobre contextos concretos estudados em $\boldsymbol{G}_{1}$ e $\mathbf{G}_{2}$ (SODRÉ, 2019, p. 24-25).

Esses gestos $\mathbf{G}_{1}, \mathbf{G}_{2}$ e $\mathbf{G}_{3}$ preservam o caráter cíclico da MM como uma OPC e, com isso, apresentamos a proposição de Sodré (2019) do CIMM ampliado de Sodré e Guerra (2018), por incluir novos tipos de Tarefas e Subtarefas, a fim de criar condições que minimizem a complexidade do ensino da MM escolar como um tipo de OPC, conforme descrito a seguir.

\section{RECONSTRUÇÃO DO CICLO INVESTIGATIVO DE MODELAGEM MATEMÁTICA}

0 CIMM, em sua versão ampliada à proposta provisória apresentada por Sodré e Guerra (2018), emergiu de análises e sínteses sobre o uso do PEP Orientado proposto por Sodré (2019) e é dotado de seis tarefas sequenciais, nem todas sempre necessárias, e se reinicia sempre que ajustes são demandados por novos questionamentos sobre as "situações concretas" e/ou artificiais.

\section{Tarefa $\mathrm{T}_{0}$ : Construir uma Situação de Referência}

A tarefa que envolve a construção de uma situação de referência tem objetivo de encaminhar 0 modo de pensar inicial, sempre provisório, ou seja, inclui considerar uma situação, mesmo que não seja a situação ideal, relacionada ao problema estudado.

Essa situação tem o papel de orientar a investigação dos modelos matemáticos pré-existentes na literatura escolar, inclusive disponíveis em fontes, como a internet, além de servir de protótipo para a empiria demandada pelas demais tarefas.

A técnica dessa tarefa consiste em considerar um problema do mesmo tipo com todos os dados conhecidos, inclusive, os dados planejados para serem encontrados, de maneira a prover uma situação de referência.

\section{Tarefa $\mathrm{T}_{1}$ : Investigar os modelos matemáticos existentes na instituição escolar relacionados ao problema}

Essa tarefa se insere nos gestos $\boldsymbol{G}_{1}$ e $\boldsymbol{G}_{2}$ com objetivo de encontrar os modelos matemáticos disponíveis na literatura escolar que podem potencialmente ser usados para a situação de referência.

Aqui é preciso ter em conta a complexidade matemática dos modelos matemáticos para 0 estudo do tipo de problema. Essa é uma questão vital para o estudo, pois quanto maior for a exigência do conhecimento matemático, melhores serão as condições para 0 (re)conhecimento de situações sobre a realidade estudada, embora sem total segurança. Além disso, o conhecimento matemático da comunidade de estudo é limitado pela escola por meio de currículos e programas e isso pode se constituir em restrições.

Situações não imaginadas em um dado contexto podem se revelar com 0 uso do modelo, principalmente, a partir de modelos matemáticos que governam situações sociais, como 0 modelo matemático do problema de financiamentos.

Segundo a compreensão adotada pela TAD, quanto maior o conhecimento de uma pessoa sobre situações com matemática, ou seja, situações que admitem praxeologias com matemática, maior será a possibilidade de encontrar ou construir uma situação que contemple a praxeologia matemática. 
Esse é o objetivo da tarefa seguinte, que também atende os gestos $\boldsymbol{G}_{1}$ e $\boldsymbol{G}_{2}$.

\section{Tarefa $\mathrm{T}_{2}$ : Encontrar a situação que define a praxeologia matemática}

Essa tarefa se insere nos gestos $\boldsymbol{G}_{1}$ e $\boldsymbol{G}_{2}$, no que tange a conhecer/reconhecer as questões, situações associadas à praxeologia com matemática.

A técnica é a análise, ou seja, desconstruir para reconstruir situações a partir da praxeologia com matemática, o que inclui os tipos de problemas a ela associados.

É preciso também observar que um homem pode ser confrontado com uma situação na qual ele vê apenas determinado aspecto, e que a construção de um modelo pode obrigá-lo a lançar um olhar mais agudo sobre a situação e descobrir características as quais, no início, ele não observara. Saber mais pode ajudar a ver mais ${ }^{11}$ (REVUZ, 1971, p. 50, tradução nossa).

As desconstruções das praxeologias matemáticas deverão ir desenhando situações por meio do encontro com relações mais profundas entre as "variáveis", as quais, embora sejam tomadas como números, são numerais que designam alguma quantidade de grandezas em contexto e, portanto, dotadas de sentidos práticos não alcançados pelos saberes matemáticos, a fim de delimitar a região de valores que essa quantidade de grandeza pode assumir.

A análise das praxeologias com matemáticas encaminha 0 encontro com as situações, como uma formulação reversa, do modelo matemático à situação que a formulação do modelo representa.

\section{Tarefa $\mathrm{T}_{3}$ : Avaliar os modelos matemáticos}

Essa tarefa se insere no gesto $G_{2}$ como parte final do estudo de modelos matemáticos. A avaliação é realizada e os critérios são a adequabilidade e a multivalência desses modelos, as quais são avaliadas frente à situação de referência. A técnica é encaminhada pelas seguintes subtarefas interconectadas:

\section{Subtarefa $\mathrm{S}_{\mathrm{T} 31}$ : Avaliar a adequação das situações reconstruídas frente ao problema}

A adequação do modelo matemático não é uma questão matemática, mas é uma questão vital para 0 estudo da realidade que trata 0 tipo de problema em contexto, pois se alguém usa um modelo inadequado, por causa de sua conveniência, simplicidade, por exemplo, sem observar sua inadequação frente à situação, é preciso estar ciente do perigo de tirar conclusões sobre a realidade a partir do estudo de tal modelo (REVUZ, 1971, p. 49).

\section{Subtarefa $\mathrm{S}_{\mathrm{T} 32}$ : Avaliar a multivalência da praxeologia com matemática e situações associadas frente ao tipo do problema}

São preferíveis as praxeologias com objetos matemáticos que dão conta de diferentes tipos de situações e, em consequência, diferentes questões sobre a realidade considerada, em lugar de praxeologias com matemáticas que somente dão conta de uma situação particular específica. Em resumo, os modelos matemáticos avaliados devem ser encaminhados à tarefa seguinte.

11 Fragmento do texto: One must also remark that a man can be confronted with a situation of which he sees only certain aspects, and that the building of a model may compel him to throw a more acute look on the situation and discover features of which, at the beginnng, he was not aware. To know more may help to see more. 


\section{Tarefa $\mathrm{T}_{4}$ : Desenvolver o modelo matemático}

Essa tarefa se insere no gesto $\boldsymbol{G}_{3}$ e, portanto, dedica-se a manter, modificar ou criar um modelo matemático a partir dos modelos matemáticos até então estudados nas tarefas anteriores.

A resposta a essa tarefa é produto das respostas das tarefas anteriores. Assim, apontamos os seguintes resultados:

1 - Manutenção de um dos modelos estudados como o modelo matemático;

2 - Modificações, inclusive de customização, de um dos modelos matemáticos anteriores;

3 - Articulação e integrações praxeológicas, o que inclui as situações associadas.

A experiência da comunidade de estudo é determinante para o desenvolvimento do modelo, além da influência, nem sempre clara, dos níveis de co-determinação didática como recursos materiais disponíveis e usados, por exemplo, calculadoras e/ou computadores, que condicionam, em geral, a comunidade de estudo na execução da tarefa superestrutural de MM.

Vale observar que a formulação do modelo matemático começa com as tarefas anteriores, a Tarefa se desenvolve nas Tarefas $\mathrm{T}_{2}$ e $\mathrm{T}_{3}$ e com 0 amadurecimento da situação com matemática referente à situação de referência que atinge a Tarefa $\mathrm{T}_{4}$ e consolida-se na Tarefa $\mathrm{T}_{5}$ seguinte.

\section{Tarefa $\mathrm{T}_{5}$ : Difundir e defender 0 modelo matemático desenvolvido}

Essa tarefa se insere no gesto e tem como objetivo difundir o modelo matemático desenvolvido com sua defesa em situação.

A técnica para essa tarefa consiste em duas fases:

I - "Aplicar" o modelo matemático desenvolvido na situação de referência, se possível com diferentes conjuntos dados, mas considerando como desconhecidos os dados de interesse do problema em estudo. A demonstração da consistência das respostas obtidas pelo modelo com a resposta conhecida, legitima o modelo matemático para a situação de referência;

II - "Aplicar" o modelo matemático desenvolvido ao problema real com os dados originais. A razoabilidade das respostas obtidas com a repetição do uso do modelo com diferentes dados possíveis para o contexto do problema encoraja a legitimidade do modelo matemático para o tipo de problema em estudo.

0 sucesso alcançado simultaneamente nas duas fases legitima provisoriamente o modelo matemático como resposta para o tipo de problema em estudo. A falha em uma delas evidencia 0 insucesso do modelo e, isso, demanda ajustes na situação de referência e novo ciclo deve ser iniciado, não necessariamente, da primeira tarefa.

De modo a ratificar ou retificar nossos pressupostos teórico-metodológicos aqui esboçados, foi desenvolvido, com o uso empírico do CIMM proposto por Sodré (2019), um curso de vinte horas para alunos do ensino médio da Escola de Aplicação da Universidade Federal do Pará (EA/UFPA), como parte integrante do Projeto de Pesquisa Modelagem Matemática Escolar vinculado ao Programa Institucional de Bolsas de Iniciação Científica Ensino Médio (PIBIC-EM), da Pró-Reitoria de Pesquisa e Pós-Graduação da Universidade Federal do Pará (PROPESP/UFPA). 


\section{ANÁLISE DA EMPIRIA: RECONSTRUÇÃO DO CICLO INVESTIGATIVO DE MODELAGEM MATEMÁTICA}

Na reconstrução do CIMM (SODRÉ, 2019), este utilizado como dispositivo didático-metodológico a ser posto à prova da contingência com alunos do ensino médio, foi encaminhado em um curso para 0 quantitativo de vinte (20) alunos designados simbolicamente por: $\mathrm{X}=\left(\boldsymbol{x}_{1}, \boldsymbol{X}_{2}, \boldsymbol{X}_{3}, \ldots, \boldsymbol{X}_{18}, \boldsymbol{X}_{19}, \boldsymbol{X}_{20}\right)$. Os alunos divididos em quatro grupos com cinco alunos constituíram os sistemas didáticos instalados na dinâmica de investigação, aqui simbolizados por: $\boldsymbol{S}=\left(\boldsymbol{S}_{1}, \boldsymbol{S}_{2}, \boldsymbol{S}_{3}, \boldsymbol{S}_{4}\right)$, sob a orientação do diretor de estudos $\boldsymbol{d}$, constituído por dois professores pesquisadores da Escola de Aplicação da Universidade Federal do Pará, designados por: $\boldsymbol{d}=\left(\boldsymbol{d}_{1}, \boldsymbol{d}_{2}\right)$.

Vale destacar que os dados empíricos desta investigação foram coletados a partir dos registros fotográficos conceituais revelados pelos sistemas didáticos tanto no processo de estudos quanto na fase de difusão e defesa das respostas obtidas, além é claro, dos diários de bordos dos pesquisadores, com o propósito de melhor coletar e apontar as manifestações espontâneas dos sistemas didáticos. Nesse sentido, "os registros conceituais são concebidos como as ideias matemáticas mobilizadas pelos alunos nas decisões para a validação ou não dos modelos em debate, evidenciando, por meio de elementos simbólicos, objetos matemáticos que justifiquem ou expliquem o fazer dos sujeitos envolvidos na atividade" (SODRÉ; ESPÍRITO SANTO, 2013, p. 84).

0 processo de estudos se deu por meio da proposição de investigações de situações reais, em particular, as de matemática financeira, cujo foco foi problema de investimento de capitais em poupança, sugerido por um dos grupos de alunos da classe. Essa escolha, inclusive, vai ao encontro dos propósitos da unidade temática de Números da Base Nacional Comum Curricular, daqui em diante BNCC, sobre "o estudo de conceitos básicos de economia e finanças, visando à educação financeira dos alunos. Assim, podem ser discutidos assuntos como taxas de juros, inflação, aplicações financeiras (rentabilidade e liquidez de um investimento) e impostos" (BRASIL, 2017, p. 269).

- Situação-problema específica - $\mathbf{Q}_{0}$ : Como determinar o valor a ser recebido em uma poupança ao final de um período de 3 (três) meses, quando uma pessoa investir inicialmente $\mathrm{R} \$ 500,00$ ?

0 processo de estudos empreendido pelos sistemas didáticos auxiliares revelou alguns questionamentos, em particular, pela manifestação do sistema didático $\boldsymbol{S}_{3}$ : $\boldsymbol{Q}_{1}$ - Qual a taxa de ganho na poupança?

Após consultar em sites da internet, usados como fontes de pesquisa, os sistemas didáticos elegeram por meio de um consenso, o valor aproximado de meio por cento ao mês ( $0,5 \%$ ao mês).

0 questionamento $\boldsymbol{Q}_{0}$ encaminhou os sistemas didáticos às seguintes tarefas:

- Tarefa $T_{0}$ - Construir uma Situação de Referência: Nessa tarefa, os sistemas didáticos auxiliares instalados $\boldsymbol{S}_{1}, \boldsymbol{S}_{2}, \boldsymbol{S}_{3}, \boldsymbol{S}_{4}$ construíram situações de referências, embora, em alguns casos, não fosse evidenciada a situação ideal em relação ao tipo de problema considerado.

Nesse sentido, é preciso destacar a arguição de Revuz (1971):

Considerar uma situação é o primeiro processo de abstração: considerando uma situação, mantemos da realidade apenas as características que pensamos ser relevantes 
para a nossa ação. Por natureza, uma situação não pode ser estritamente determinada, e, em vez de abstrair, precisamos falar em isolar, por certo tempo, a situação ${ }^{12}$ (REVUZ, 1971, p. 49, tradução nossa).

A situação de referência orientou a investigação de modelos matemáticos pré-existentes na literatura escolar. Figura 2.

A técnica $T_{0}$ da tarefa consistiu no uso dos dados do problema, conforme depreendemos da

Figura 2 - Registro do sistema didático auxiliar $S_{4}\left(x_{16}, x_{17}, x_{18}, x_{19}, x_{20}, \wp\right)$

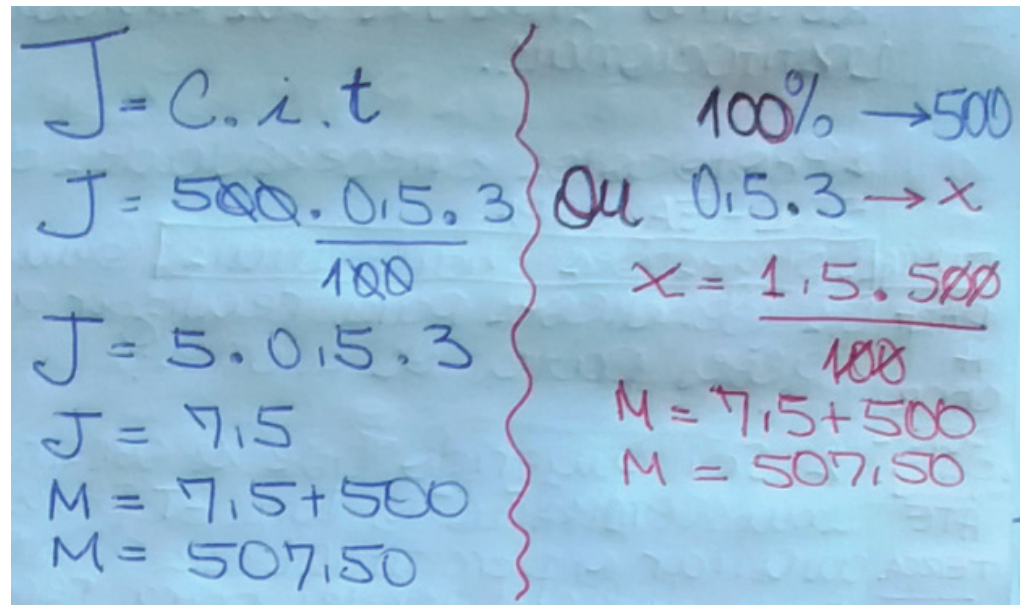

Fonte: acervo da pesquisa (2019).

Dois modelos matemáticos $\wp_{1}$ e $\wp_{2}$ para 0 tipo do problema foram destacados pelo sistema didático auxiliar $\mathbf{S}_{4}$ instituído pelos diretores de estudos $\mathbf{d}_{1}$ e $\mathbf{d}_{2}$. 0 registro desse sistema didático, constituído por alunos do segundo e terceiro anos do ensino médio, revelou o uso de dois modelos matemáticos pré-existentes na instituição escolar: 0 de juros simples, aqui designado por $\wp_{1}$, e 0 de regra de três simples por meio do discurso da quarta proporcional, aqui designado por $\wp_{2}$, da aritmética prática. Embora esses modelos encaminhem objetivamente a mesma resposta numérica, são entidades praxeológicas distintas (CHEVALLARD, 2009b) por envolverem maneiras de fazer e de pensar diferentes entre si.

É preciso considerar que o processo de estudos levou em conta, de modo particular, o principio da dúvida metódica que, segundo Chevallard (2009a), pode ser compreendido como qualquer afirmação recolhida, neste caso, pelos sistemas didáticos auxiliares $\boldsymbol{S}$, sobre as questões e/ou a pesquisa realizada no percurso, seja tomado fundamentalmente como conjectural, isto é, não se pode acreditar ou rejeitar a priori (CHEVALLARD, 2009a) o modelo matemático considerado como resposta.

Nesse sentido, a situação de referência orientou a investigação de modelos matemáticos pré-existentes na literatura escolar.

12 Fragmentos do texto: To consider a situation is a first process of abstraction: considering a situation, we keep only from reality the features that we think relevant to our action. By nature, a situation can't be strictly determined, and rather than of abstracting, one should speak of isolating, for a certain time, the situation. 
Tarefa $T_{1}$ - Investigar os modelos matemáticos existentes na instituição escolar referentes ao problema: Essa tarefa levou os sistemas didáticos auxiliares à investigação de modelos matemáticos disponíveis na literatura escolar que foram potencialmente utilizados na situação de referência.

A técnica $\tau_{1}$ da tarefa $\tau_{1}$ consistiu no uso de modelos matemáticos presentes entre os objetos da escola básica, além da manifestação espontânea do sistema didático $\boldsymbol{S}_{1}$, que, embora considere uma organização praxeológica estruturada por meio do modelo matemático $\wp_{2}$ da regra de três simples, dotado de um jeito de fazer e de pensar, cujo modelo não foi necessariamente 0 mesmo revelado por $\mathbf{S}_{1}$. É preciso observar que $\mathbf{S}_{1}$ assumiu um tipo de situação matematizável com um modo de fazer e de pensar distinto do modelo matemático $\wp_{2}, 0$ qual encaminhou a situação que define a praxeologia matemática, conforme orienta a Figura 3.

Figura 3 - Registro do sistema didático auxiliar $\boldsymbol{S}_{1}\left(\boldsymbol{x}_{1}, \boldsymbol{x}_{2}, \boldsymbol{x}_{3}, \boldsymbol{x}_{4}, \boldsymbol{x}_{5}, \wp_{3}\right)$.
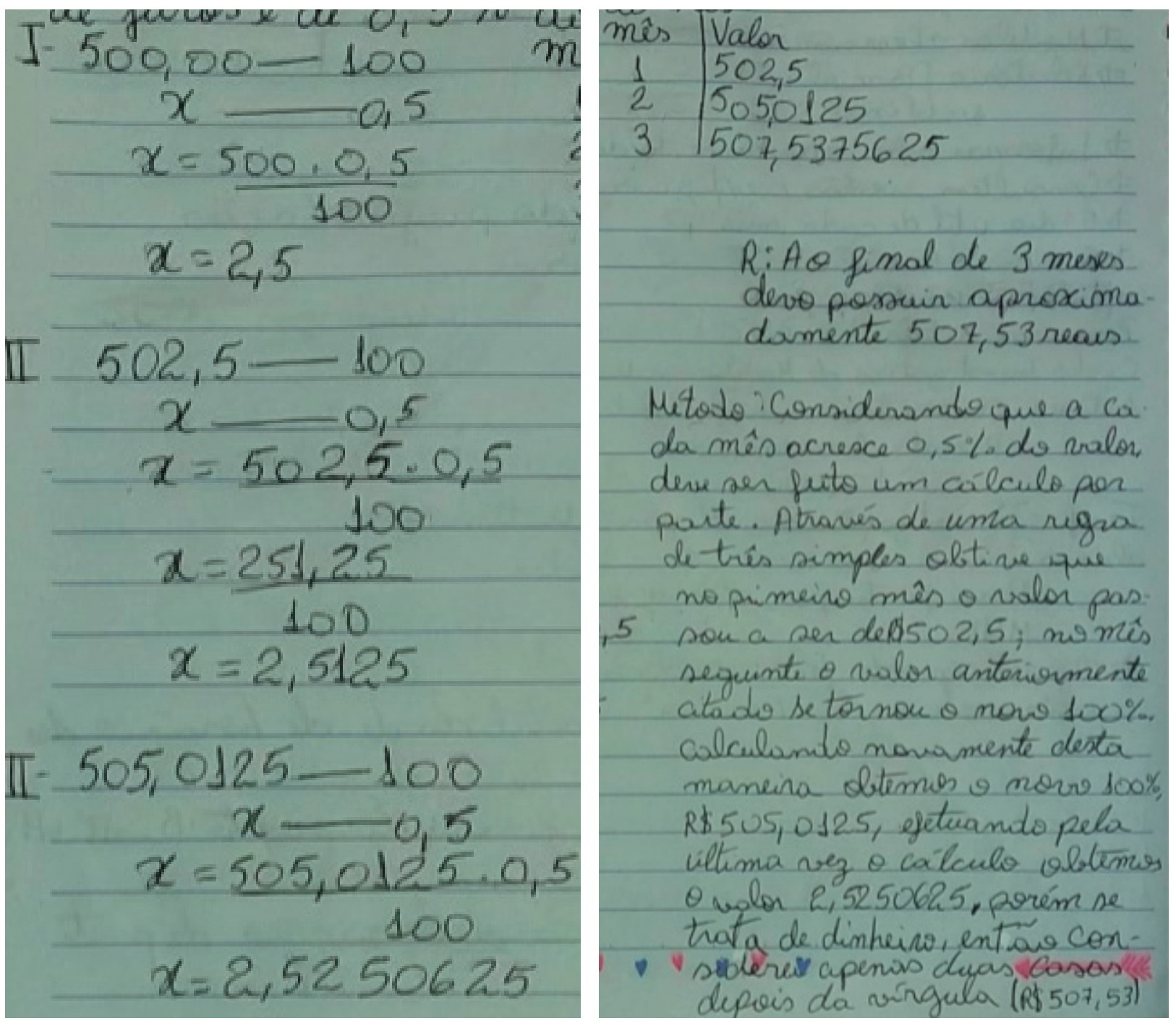

Fonte: acervo da pesquisa (2019). 


\section{Transcrição do registro em linguagem natural do sistema didático}

R: Ao final de 3 meses devo possuir aproximadamente 507,53 reais.
Método: Considerando que cada mês acresce $0,5 \%$ do valor deve ser feito um cálculo por
parte. Através de uma regra de três simples obtive que no primeiro mês o valor passou a ser
de $\mathrm{R} \$ 502,5$, no mês seguinte o valor anteriormente citado se tornou o novo $100 \%$. Calculando
novamente desta maneira obtemos o novo $100 \%, \mathrm{R} \$ 505,0125$, efetuando pela última vez
o calculo obtemos o va-lor de $\mathrm{R} \$ 2,5250625$. Porém se trata de dinheiro, então considerei
apenas de duas casas decimais depois da vírgula ( $\mathrm{R} \$ 507,53$ ).

Fonte: autor da pesquisa (2020).

Os encaminhamentos do sistema didático auxiliar $\mathbf{S}_{1}$ constituído, em particular, por alunos do primeiro ano do ensino médio, colocou em jogo um modo de fazer e de pensar distinto do que apresentou o sistema didático auxiliar $\mathbf{S}_{\mathbf{4}}$, por revelar em sua manifestação uma situação divergente da situação apresentada por $\mathbf{S}_{4}$, ao utilizar a regra de três. Embora os modos de fazer pareçam similares na organização praxeológica do modelo matemático, a maneira de pensar é outra, isto é, mudanças na situação considerada muda também o modelo matemático. De outra forma, "alterações e recombinações praxeológicas são, portanto, um fenômeno no coração da história social das praxeologías ${ }^{13}$ (CHEVALLARD, 2009a, p. 4, grifos do autor, tradução nossa).

A organização praxeológica revelada pelo $\boldsymbol{S}_{1}$, aqui designada pelo modelo matemático $\wp_{3}$, parece se apoiar sobre o discurso de um saber não necessariamente teórico, mas prático de regra de três simples que permitiu, além do encontro com outros saberes matemáticos, o encontro com saberes não matemáticos, em particular, com 0 uso da calculadora científica, dada à complexidade que emergiu com a necessidade de operar com números decimais.

É preciso destacar que os cálculos feitos com 0 uso de calculadora científica não eram do conhecimento de grande parte dos alunos. Isso detonou um sistema didático auxiliar $\boldsymbol{S}=\left(\boldsymbol{S}_{1}, \boldsymbol{d}_{1}\right.$, $\boldsymbol{d}_{2}, \wp_{\mathrm{c}}$ ), em que $\wp_{\mathrm{c}}$ designa "as praxeologias relativas às tarefas de cálculo na calculadora científica, inclusive, com respeito à aritmética de pontos flutuantes, como arredondamento e truncamento" (SODRÉ; GUERRA, 2018, p. 258), como observa o sistema didático $S_{1}$ "(...) se trata de dinheiro, então considerei apenas de duas casas decimais depois da vírgula ( $R \$ 507,53)$ " (Transcrição do registro em linguagem natural do sistema didático $\boldsymbol{S}_{1}$ ).

Além disso, a manifestação do sistema didático $S_{1}$ permitiu o encontro de uma situação que, em passos sucessivos, começou a definir a praxeologia matemática, conforme orienta a tarefa $\mathrm{T}_{2}$ :

- Tarefa $T_{2}$ - Encontrar a situação que define a praxeologia matemática: Essa tarefa inclui 0 conhecimento/reconhecimento da situação associada à praxeologia com matemática $\wp_{3}$.

A técnica $\mathrm{T}_{2}$ dessa tarefa consistiu na análise, ou seja, desconstruir para reconstruir situações a partir da praxeologia com matemática descrita pelo modelo matemático que $\wp_{3}$ contrastou com a situação de juros simples difundida pelo sistema didático $S_{4}$, mesmo que provisoriamente, como resposta a partir do modelo matemático $\wp_{1}$.

É importante destacar que 0 uso de um modelo matemático como $0 \wp_{1}$ revelado pelos alunos, 13 Fragmento do texto: Les altérations et recombinaisons praxéologiques sont ainsi un phénomène au cœur de l'histoire sociale des praxéologies. 
não necessariamente assegura ou garante 0 conhecimento da situação em contexto associada ao modelo, como orienta o registro da Figura 4, avaliado e contrastado frente ao modelo $\wp_{3}$ desenvolvido pelo sistema didático $\boldsymbol{S}_{1}$.

Figura 4 - Registro do sistema didático auxiliar

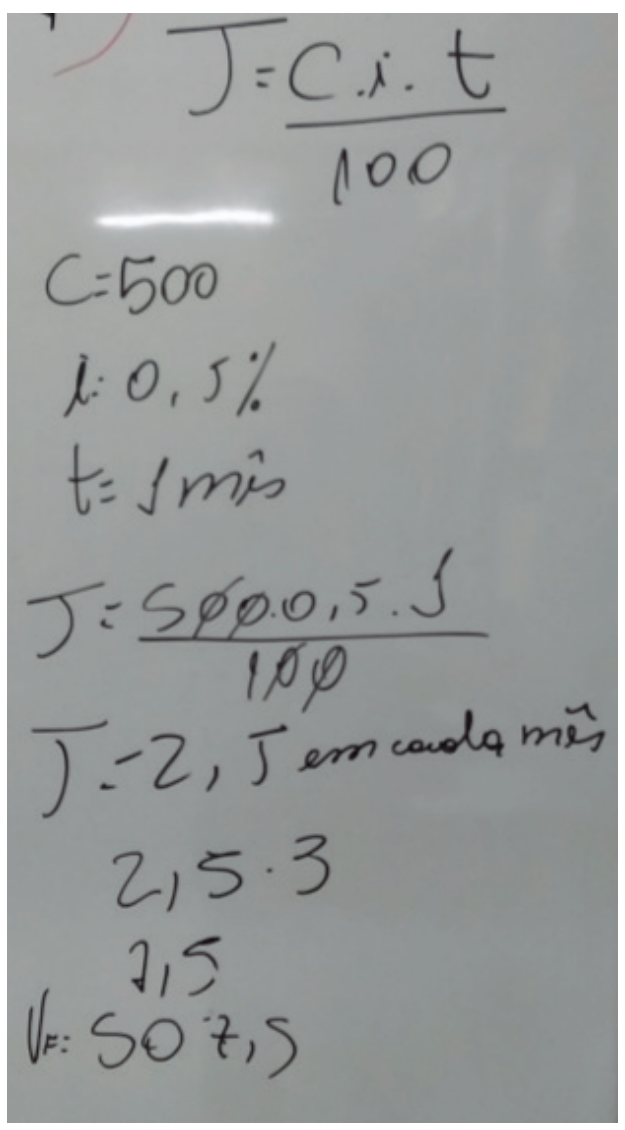

Fonte: acervo da pesquisa (2019).

Nesse sentido, Sodré e Guerra (2018) e Sodré (2019) enfatizam que as praxeologias da Matemática Financeira se mostraram complexas para quem não é agente do sistema financeiro, pois o conhecimento da situação com o modelo matemático associado está ao alcance somente daqueles sujeitos que possuem o filtro de percepção da situação (CHEVALLARD, 2005), porque, nesses contextos, "criação da cultura, são explicitamente regulados, às vezes de maneira muito precisa, por convenção social. É 0 caso das transações financeiras, empréstimos de capital, etc., práticas sociais que são de fato definidas a priori por um modelo matemático ${ }^{14}$ (CHEVALLARD, 1989, p. 27, grifos do autor, tradução nossa).

De qualquer modo, é preciso considerar o que afirma Chevallard (2005, p. 171, tradução nossa) "que entre um saber e uma prática existe uma distância nunca inteiramente abolida"15.

0 saber de um domínio da realidade é um saber sobre as práticas sociais relacio-

14 Fragmento do texto: (...)création de la culture, sont explicitement réglés, de manière parfois fort précise, par convention sociale. C'est le cas des transactions financières, du prêt à intérêt, etc., pratiques sociales qui sont en fait définies a priori par un modèle mathématique. 15 Fragmento do texto: que entre un saber y una práctica hay una distancia nunca enteramente abolida. 
nadas a esse domínio da realidade, que sem dúvida tem sua relevância para essas práticas. Mas sua congruência em relação a eles, aquilo que o constituiria no saber dessas práticas, nunca é garantida (CHEVALLARD, 2005, p. 172, grifos do autor, tradução nossa).

0 conhecimento dos alunos sobre 0 uso do modelo matemático $\wp_{1}$ da situação de juros simples não assegura a esses alunos o conhecimento da situaçãa que define o modo de fazer e de pensar sobre o tipo de problema de investimento. Ou seja, os saberes em sentido amplo, incluindo os saberes práticos, que conformam a prática social das instituições financeiras, não são alcançados ou não se fazem visíveis em um modelo matemático, o que revela parte da complexidade dos saberes que conformam as práticas sociais.

0 processo de estudos desenvolvido pelos sistemas didáticos que levou ao encontro de modelos matemáticos pré-existentes na literatura escolar permitiu, mas não somente, o estudo de uma variedade de situações de juros simples, em articulação e integração com outros saberes da escola básica, como orienta a Figura 5.

Figura 5 - Registro do sistema didático auxiliar $\boldsymbol{S}_{3}\left(\boldsymbol{x}_{11}, \boldsymbol{x}_{12}, \boldsymbol{x}_{13}, \boldsymbol{x}_{14}, \boldsymbol{x}_{15}, \wp_{1}\right)$.

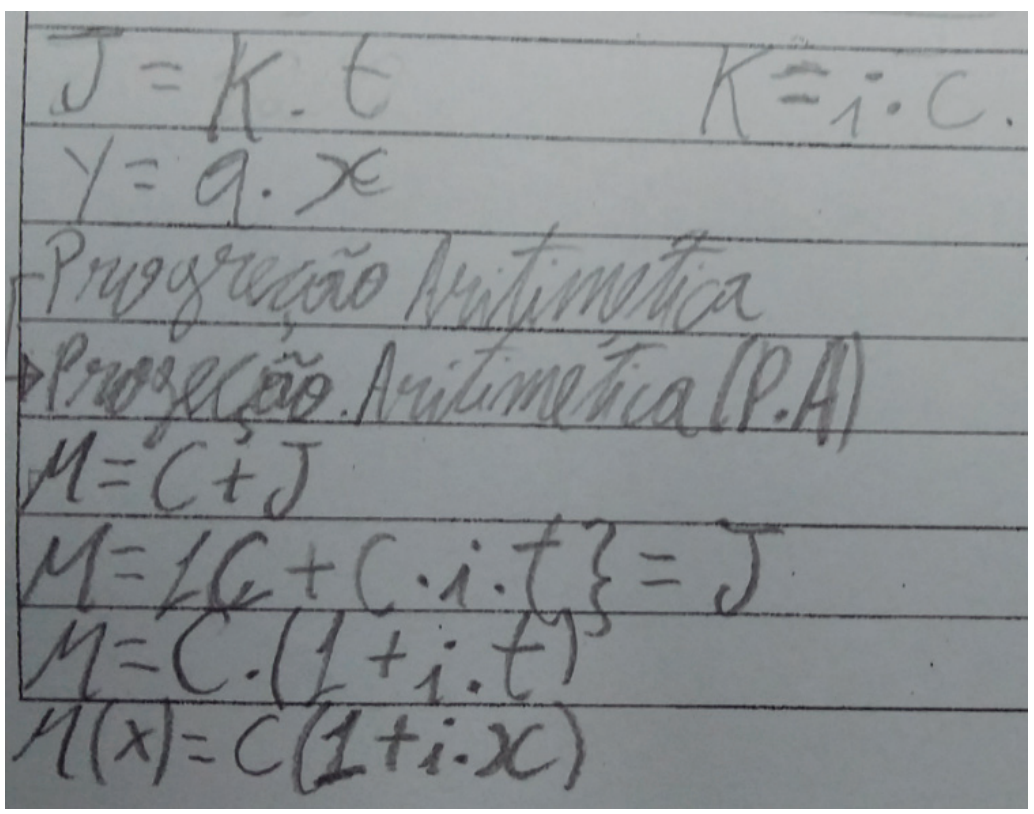

Fonte: acervo da pesquisa (2019).

0 registro do sistema didático $S_{3}$ encaminha uma relação de semelhança de família, no sentido de Wittgenstein (1999), entre diferentes objetos de ensino da matemática escolar, por meio de analogias que permitiram "o cumprimento de várias tarefas diferenciadas graças à transferência analógica de 'esquemas', adquiridos em uma prática anterior" (BOURDIEU, 2002 [1972], p. 261), em particular, mediante os seguintes objetos: 
a) a noção de juros expressa por: $\boldsymbol{J}=\boldsymbol{K} \cdot \boldsymbol{t}$, sendo $(\boldsymbol{K}=\boldsymbol{i} . \boldsymbol{C})$;

b) a noção de função linear dada por: $\boldsymbol{Y}=\boldsymbol{a} \cdot \boldsymbol{x}$;

c) a noção de Progressão Aritmética (P. A.).

Essas estruturas apresentadas em (a), (b) e (c) podem ser compreendidas como praxeologias matemáticas customizadas (SODRÉ, 2019), isto é, são praxeologias que podem ser adaptadas em um dado contexto, mas que possui a mesma estrutura da equação matemática: $\boldsymbol{z}=\boldsymbol{x}$.y. Dependendo do tipo de contexto ou campo de práticas em que se manipulam as variáveis e/ou suas relações entre si, com o propósito de atender os interesses institucionais, a praxeologia matemática customizada passa a ser dotada de sentidos práticos diferentes, como por exemplo: $\boldsymbol{F}=\boldsymbol{m} . \boldsymbol{a}$. No contexto da física escolar, as grandezas modeladas por $\boldsymbol{F}, \boldsymbol{m}$ e $\boldsymbol{a}$ assumem sentidos práticos como as noções de força $(\mathbf{F})$, massa $(\mathbf{m})$ e aceleração (a), respectivamente, específicas da instituição física escolar. Cada registro com uso de letra do alfabeto não é por acaso, pois passam a designar uma grandeza de um ente do campo de prática específico. De outro modo, a praxeologia matemática customizada "é subordinada à cultura das práticas institucionais a que está vinculada" (SODRÉ, 2019, p. 42).

Em última análise, o resultado da articulação e integração entre as praxeologias, "obtido com 0 objetivo de produzir conhecimentos sobre o sistema em estudo, que tomem a forma de novas relações entre as variáveis do sistema"16 (CHEVALLARD, 1989, p. 53, grifos do autor, tradução nossa), encaminhou ao modelo matemático $\wp_{4}$ algebrizado para 0 cálculo do montante: $\wp_{4}=\boldsymbol{M}(\boldsymbol{x})=\boldsymbol{C} .(1+\boldsymbol{i} . \boldsymbol{x})$ da situação de juros simples.

A avaliação dos modelos matemáticos estudados permitiu encaminhar e legitimar 0 estudo da obra que reportou situações à praxeologia com matemática materializada pelo modelo $\wp_{3}$ assumido até então como resposta, conforme orienta a tarefa seguinte.

- Tarefa $T_{3}$ - Avaliar os modelos matemáticos: Essa tarefa assume como critérios a adequabilidade e a multivalência dos modelos analisados.

A técnica $\mathbf{T}_{3}$ é encaminhada pelas seguintes subtarefas e interconectadas:

$S_{T 31}$ : Avaliar a adequação das situações reconstruídas frente ao problema;

$S_{T 32}$ : Avaliar a multivalência da praxeologia com matemática e situações associadas frente ao tipo do problema.

A avaliação dos modelos matemáticos $\wp_{1}, \wp_{2} \mathrm{e} \wp_{3}$ das situações de juros simples, de regra de três e de juros compostos respectivamente, frente ao tipo de problema levou além da legitimação do modelo $\wp_{3}$ pela comunidade de estudo, a criação do modelo matemático do cálculo $\wp_{4}$ do montante da situação de juros simples, em particular, após o levantamento de obras consultadas pelos alunos na investigação. A tarefa de avaliar os modelos levou em conta a adequação das situações com 0 modelo matemático $\wp_{3}$ de juros compostos e sua multivalência (REVUZ, 1971) no estudo de outras situações, incluindo, situações de contextos reais, envolvendo compras em cartões de créditos, conforme orientam os objetivos da tarefa seguinte.

- Tarefa $\mathbf{T}_{4}$ - Desenvolver o modelo matemático: Nessa tarefa, toma-se como objetivo manter, modificar ou criar um modelo matemático a partir dos modelos matemáticos até então estudados nas tarefas anteriores.

16 Fragmento do texto: obtenu, dans le but de produire des connaissances relatives au système étudié, connaissances qui prennent la forme de nouvelles relations entre les variables du système. 
A técnica $T_{4}$ pode resultar de:

1 - Manutenção de um dos modelos estudados como o modelo matemático;

2 - Modificações, inclusive de customização, de um dos modelos matemáticos anteriores;

3 - Articulação e integrações praxeológicas, 0 que inclui as situações associadas.

Vale ressaltar que a formulação do modelo matemático $\wp_{3}$ de juros compostos começou com as tarefas anteriores, e substanciou-se nas tarefas $T_{2}$ e $T_{3}$, atingindo a tarefa $T_{4} e$, consolidou-se, na tarefa $T_{5}$ seguinte.

- Tarefa $\boldsymbol{T}_{5}$ - Difundir e defender 0 modelo matemático desenvolvido: Essa tarefa tem como objetivo difundir o modelo matemático $\wp_{3}$, considerando a seguinte técnica:

A técnica $\boldsymbol{T}_{5}$ consiste de modo geral, em considerar a razoabilidade das respostas obtidas com a repetição do uso do modelo matemático com diferentes dados possíveis, que encorajou a legitimidade do modelo matemático $\wp_{3}$ de juros compostos pelos sistemas didáticos $\boldsymbol{S}=\left(\boldsymbol{S}_{1}, \boldsymbol{S}_{2}, \boldsymbol{S}_{3}, \boldsymbol{S}_{4}\right)$ para 0 tipo de problema em estudo, ao alcançar uma construção algébrica mais consistente com a formulação do modelo matemático algébrico $\wp_{5}$ de juros compostos, como orienta a Figura 6 .

Figura 6 - Registro do sistema didático auxiliar $S=\left(\boldsymbol{x}_{11}, \boldsymbol{x}_{12}, \boldsymbol{x}_{13}, \boldsymbol{x}_{14}, \boldsymbol{x}_{15}, \wp_{5}\right)$.

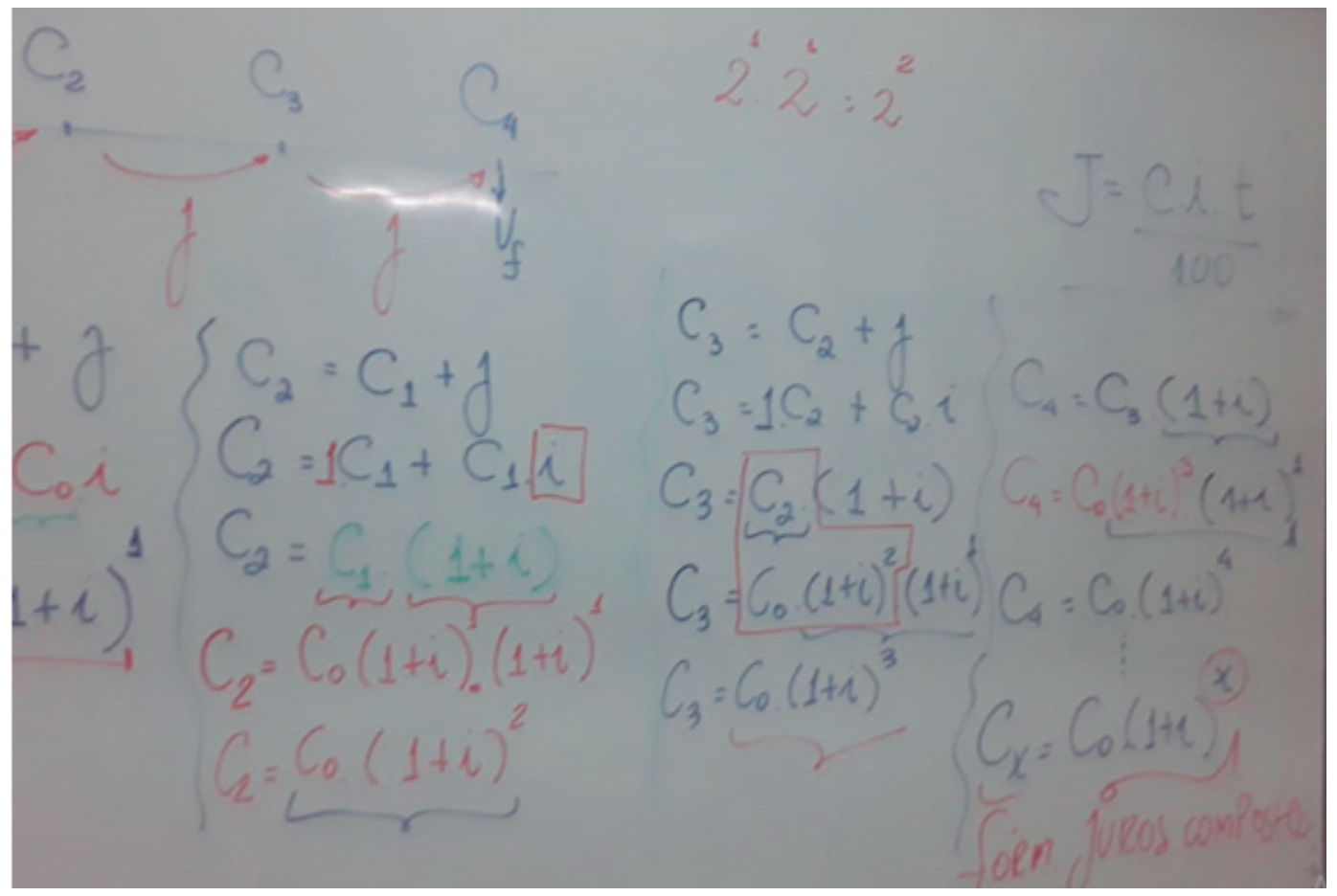

Fonte: acervo da pesquisa (2019).

0 registro do sistema didático $S_{3}$ apresentado pelo aluno $x_{12}$, conforme a Figura 6, destacou na fase de socialização e defesa do modelo matemático algébrico $\wp_{5} 0$ uso do "fluxo de caixa" como ferramenta ou gesto didático que orientou de modo determinante desconstruções e reconstruções dos modelos matemáticos até então esboçados. Essa dinâmica, que incluiu a mobilização dos modelos matemáticos $\wp_{1}, \wp_{2}, \wp_{3}$ e $\wp_{4}$, encaminhou a reconstrução algébrica do modelo matemático $\wp_{5}$ 
em sentido mais amplo e ergonômico em relação ao modelo $\wp_{3}$, formulado com saberes da prática escolar de regra de três simples.

0 esquema do "fluxo de caixa" foi indispensável para orientar na formulação do modelo $\wp_{5} \mathrm{e}$, como tal, pode ser compreendido como um "gesto didático - de modo que qualquer instância $\mathrm{V}$ (pessoa ou instituição) vê modificar de uma forma desejada a sua relação para com uma certa obra $\vee^{\text {"17 }}$ (CHEVALLARD, 2009b, p. 15, grifos do autor, tradução nossa). A noção de obra a que se refere 0 autor pode ser compreendida como qualquer objeto antropogênico produzido pelo homem, incluindo entre esses objetos os modelos matemáticos.

De qualquer modo, o processo de estudos provocou nos alunos alterações na qualidade de relações de aprendizagem com os saberes matemáticos e, em particular, os não matemáticos, materializados e demandados pelo uso do modelo em novas situações de estudos, como débitos em cartões de créditos, a partir de uma situação concreta, conforme orienta a Figura 7.

Figura 7 - Ilustração de uma fatura de cartão de crédito

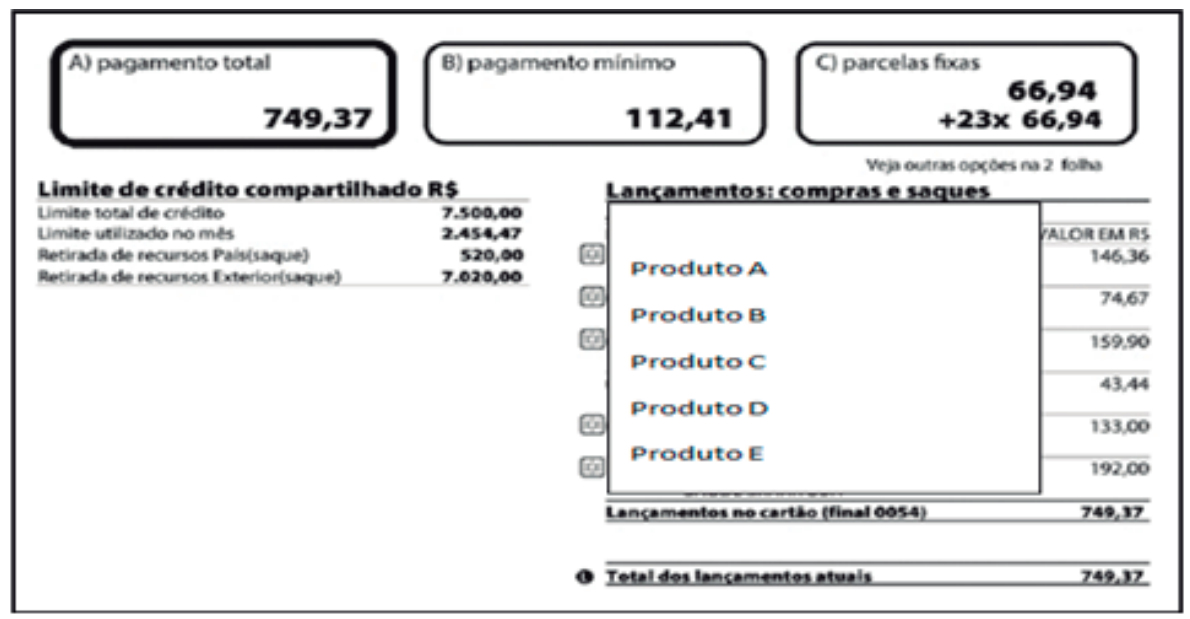

Fonte: acervo da pesquisa (2019).

A defesa do modelo matemático $\wp_{5}$ legitimado frente às situações estudadas permitiu desconstruções e reconstruções de situações pelos sistemas didáticos $(\boldsymbol{S})$, a partir da lógica prática que orienta 0 uso do cartão de crédito, estabelecendo com isso relações mais profundas com saberes não matemáticos que, em geral, parecem não se fazerem presentes explicitamente nas situações de compra e venda, mas que condicionam a prática, e esta pode, até mesmo, colocar o usuário de cartão de crédito em situações de endividamento, como depreendemos dos relatos dos sistemas didáticos $\boldsymbol{S}_{1}$ e $\boldsymbol{S}_{3}$ :

- $\boldsymbol{S}_{1}$ - não sabíamos que são cobrados tantos juros assim (...) por isso que tem muita gente endividada no nosso pais...

- $\boldsymbol{S}_{3}$ - têm outras coisas que são calculadas (...) que em geral não se enxerga nem mesmo o tamanho das letrinhas presentes nas faturas dos cartões (...) e isso dificulta o que realmente é incluído no pagamento da dívida pelo consumidor...

(Transcrição dos registros dos alunos).

17 Fragmentos do texto: "geste didactique" - afin que quelque instance V (personne ou institution) voit se modifier d'une façon souhaitée son rapport à une certaine œuvre $\boldsymbol{\varphi}$. 
A manifestação dos sistemas didáticos $\boldsymbol{S}_{1}$ e $\boldsymbol{S}_{3}$, por exemplo, parece claro sobre o condicionamento dos saberes não matemáticos que afetam as praxeologias financeiras no uso do cartão de crédito.

Com esse olhar, a reconstrução do CIMM proposto por Sodré (2019) se mostrou útil para 0 ensino e a aprendizagem de MM escolar, incluindo, desde novas relações com objetos matemáticos escolares, bem como saberes não disciplinares não matemáticos, aqui compreendidos como suporte didático (CHEVALLARD, 2019) indispensável ao estudo de problemas em contextos reais, inclusive, de interesse da escola básica, conforme orientam os documentos oficiais, como a BNCC, entre outros.

\section{CONSIDERAÇÕES E ENCAMINHAMENTOS}

0 objetivo desta investigação consistiu no uso do CIMM ampliado proposto por Sodré (2019), de modo a considerar seu alcance como dispositivo didático para o ensino da MM escolar e, com isso, permitiu minimizar a invisibilidade do condicionamento mútuo de saberes matemáticos e não matemáticos, com a clareza do papel indispensável dos saberes não matemáticos para 0 estudo de tipos de problemas da matemática financeira escolar.

A reconstrução do CIMM (SODRÉ, 2019) em sua versão ampliada se desenhou a partir das investigações de Sodré e Guerra (2018) e, como isso, incluiu três gestos genuínos da atividade de MM escolar propostos por Sodré (2019) a serem seguidos pelo diretor de estudos. Posto à prova empiricamente com alunos do ensino médio da Escola de Aplicação da Universidade Federal do Pará (EA/UFPA), o CIMM criou condições, nem todas sob certas restrições institucionais, para que a MM atinja o status de um saber ensinável no sentido da TAD, sem desconsiderar que todo saber científico funciona sob um extrato profundo de pré-construídos (CHEVALLARD, 2005).

0 CIMM proposto por Sodré (2019) busca, mas não somente, delimitar um conjunto de tarefas e técnicas tendo em vista que "toda prática institucional pode ser analisada de diferentes pontos de vista e de diferentes maneiras por meio de um sistema de tarefas relativamente bem circunscritas que serão realizadas no fluxo das práticas sociais"18 (BOSCH; CHEVALLARD, 1999, p. 5, grifos dos autores, tradução nossa), constituindo-se uma possível resposta, embora de modo provisório, para 0 tipo de problema $\mathbf{P}_{0}(\mathrm{MM})$ que, segundo Florensa, Garcia e Sala (2020), é um dos pontos de partida bastante comum nas linhas de pesquisas sobre MM.

Parafraseando Chevallard (1999), a reconstrução do CIMM buscou ratificar que em "sentido forte: a resposta agora não é uma informação simples, é toda uma organização praxeológica que está prestes a ser construída"19 (CHEVALLARD, 1999, p. 233, tradução nossa).

A reconstrução do CIMM por criar condições, embora nem todas para o ensino de MM, pode então ser compreendida no sentido da transposição didática institucional do saber (CHEVALLARD, 1999, 2005), além de confirmar alguns resultados encontrados por Sodré e Guerra (2018), mas não somente, permitiu minimizar a invisibilidade dos saberes infraestruturais, em particular, o condicionamento mútuo dos saberes matemáticos e não matemáticos que se fizeram presentes para o uso, 0 estudo ou até mesmo a (re)criação de modelos matemáticos a partir das práticas escolares.

Com esse olhar, pressupomos que a prática de MM escolar mediada pela didática do CIMM (SODRÉ, 2019) possibilitou o enfrentamento de uma das problemáticas de interesse da antropologia

18 Fragmento do texto: toute pratique institutionnelle se laisse analyser, de différents points de vue et de différentes façons, en un système de tâches relativement bien circonscrites, qui se découpent dans le flux de la pratique.

19 Fragmento do texto: (...) en sentido fuerte: la respuesta no es ahora una simple información, es toda una organización praxeológica que está por construir. 
didática, mais precisamente, a noção de ecologia dos saberes (CHEVALLARD, 1999), visto que "de um modo geral, o problema ecológico - Por que isso? Por que esse outro?, etc. - leva a questionar a realidade observável da evidência do fato estabelecido, visto como natural"20 (CHEVALLARD, 1999, p. 252, tradução nossa), ao colocar em jogo indagações de prática de MM escolar, como se esta dependesse tão somente de objetos matemáticos.

A ilusão de "naturalidade" no caso da MM se assenta sob a compreensão de enclausuramento do estudo de problemas do mundo real por meio de objetos matemáticos apenas, como se estes fossem suficientes para permitir a compreensão de um domínio de realidade. De modo distinto, os resultados empíricos postos à prova contrastaram com a perspectiva de MM que parece depender somente de objetos matemáticos, ao agregar outros saberes em sentido amplo procedimentais, desde 0 uso da calculadora científica e, até mesmo, os pré-construídos, que somente são aprendidos em situação (CHEVALLARD, 2005).

0 caminhar do processo de estudos com os alunos do ensino médio incluiu situações da matemática financeira, em particular, a situação-problema específica - $\boldsymbol{Q}_{0}$ : Como determinar 0 valor a ser recebido em uma poupança ao final de um período de 3 (três) meses de aplicação, quando uma pessoa investir inicialmente $\mathrm{R} \$ 500,00$ ?

Esse questionamento criou condições para outros questionamentos que emergiram no processo de estudos, além de propiciar o encontro dos alunos com diferentes saberes, incluindo os modelos matemáticos de situações de juros simples, de regra de três e de juros compostos demandados ao estudo da situação. As respostas encontradas foram postas à prova frente à classe, conforme orienta 0 princípio da dúvida metódica (CHEVALLARD, 2009a), segundo o qual, qualquer resposta obtida não pode ser aceita ou rejeitada a priori.

Embora os resultados empíricos significativos com alunos do ensino médio tenham sido alcançados, alguns alunos encontraram dificuldades no estudo da situação-problema específica. Mesmo que esses alunos tenham revelado qualidade de relações com o saber (CHEVALLARD, 2005), isto é, com os modelos matemáticos pré-existentes na literatura escolar para enfrentar a situação-problema, essas relações não foram suficientes para garantir ou assegurar o reconhecimento da situação adequada ao tipo de problema, pois os modelos matemáticos da matemática financeira são pré-determinados por convenções sociais (CHEVALLARD, 1989).

Essa constatação revela, em nosso entendimento, parte da complexidade que envolve a realização de uma das tarefas do CIMM, mais precisamente a Tarefa $\mathbf{T}_{2}$ - encontrar a situação que define a praxeologia matemática, cuja técnica consiste na análise dos modelos, ou seja, desconstruir para reconstruir situações a partir do modelo matemático que pode estar associado, além de evidenciar que 0 conhecimento do modelo não assegura o reconhecimento da situação.

As dificuldades explicitadas pelos alunos, a nosso ver, podem ser decorrentes da ausência dos saberes práticos no filtro de percepção (CHEVALLARD, 2005) dos alunos, que são específicos da cultura de instituições financeiras afins. Ou seja, a ausência desses saberes dificultou, senão impediu inicialmente, 0 encontro dos alunos com a situação a que se refere o tipo de problema em contexto.

0 encadeamento desses modelos estudados e investigados pelos alunos levou à construção de diferentes qualidades de relações com diferentes objetos, em particular, os objetos matemáticos, como noções de função linear e progressão aritmética, entre outros, dando sentido e significado a essas praxeologias da matemática escolar.

20 Fragmento do texto: De una manera general, la problemática ecológica -¿Por qué esto?¿Por qué esto otro?, etc.- conduce a cuestionarla realidad observable de la evidencia del hecho establecido, visto como natural. 
Em última análise, o processo de estudos permitiu o uso, o estudo e a criação de modelos matemáticos que, em algum sentido, revelaram possibilidades de enfrentamento das problemáticas pertinentes ao saber, isto é: uso, estudo e criação. Na perspectiva da TAD, nenhuma dessas dimensões do saber, aqui parafraseado pelos modelos matemáticos estudados e investigados pelos alunos, podem ser ignoradas no processo de estudo, pois "do ponto de vista da antropologia, um saber se apresenta como uma totalidade, cujos diferentes momentos são igualmente vitais"21 (CHEVALLARD, 2005, p. 155, tradução nossa).

Outros resultados teóricos podem derivar dessa compreensão de MM como uma OPC, tendo em conta 0 estudo de modelos matemáticos de maior complexidade. Esses aspectos serão objetos de investigações vindouras, cujos resultados constituirão matéria de futuras publicações, de modo a construir uma compreensão sobre o alcance empírico da reconstrução do CIMM que se desenhou a partir desta investigação com alunos do ensino básico, bem como contribuir para a formação de professores da educação básica sem desconsiderar a formação inicial e continuada.

\section{REFERÊNCIAS}

BARQUERO, B. Introduction to 'Research on the teaching and learning of mathematical modelling: Approaches for its design, implementation and analysis'. AIEM - Avances de Investigación en Educación Matemática - 2020, 17, 1-4.

BARQUERO, B.; BOSCH, M.; GASCÓN, J. Los recorridos de estudio e investigación y la modelización matemática en la enseñanza universitaria de las Ciencias Experimentales. Enseñanza de las ciencias: revista de investigación y experiencias didácticas, v. 29, n. 3, p. 339-352, 2011.

BARQUERO, B.; BOSCH, M.; GASCÓN, J. The ecological dimension in the teaching of mathematical modelling at university. Recherches en Didactique de Mathématiques, v. 33, n. 3, p. 307-338, 2013.

BARQUERO, B.; JESSEN, B. E. Impact of theoretical perspectives on the design of mathematical modelling tasks. AIEM - Avances de Investigación en Educación Matemática - 2020, 17, 98-113.

BARQUERO, Berta; BOSCH, Marianna; WOZNIAK, Floriane. Modelling praxeologies in teacher education: the cake box. Eleventh Congress of the European Society for Research in Mathematics Education, Utrecht University, Feb 2019, Utrecht, Netherlands. hal-02408705.

BLUM, W. (2011). Can modelling be taught and learnt? Some answers from empirical research. In G. Kaiser, W. Blum, R. Borromeo Ferri \& G. Stillman (Eds.), Trends in the teaching and learning of mathematical modelling (p. 15-30). Dodrecht: Springer.

BLUM, W.; LEIß, D. Modellieren im Unterricht mit der - Tanken-Aufgabe. Mathematik Lehren, v. 128, p. 18-21, 2005.

BOSCH, Marianna, CHEVALLARD, Yves. La sensibilité de l'activité mathématique aux ostensifs. Objet d'étude et problématique. Recherche en Didactique des Mathématiques, 19/1, 77-124, 1999.

BOURDIEU, P. Esboço de uma teoria da prática: precedido de três estudos de etnologia kabila. Oeiras: Celta, 2002 [1972].

21 Fragmento do texto: Desde el punto de vista de la antropología, el saber se presenta como una totalidad, cuyos diferentes momentos son igualmente vitales. 
BRASIL. Base Nacional Comum Curricular: Educação Infantil e Ensino Fundamental. Brasília: MEC/Secretaria de Educação Básica, 2017.

BRASIL. Brasil no PISA 2015: análises e reflexões sobre o desempenho dos estudantes brasileiros / OCDE - Organização para a Cooperação e Desenvolvimento Econômico. - São Paulo: Fundação Santillana, 2016.

BROUSSEAU G. (1995), L'enseignant dans la théorie des situations didactiques. Dans: Noirfalise R. et Perrin-Glorian M. J., Actes de la VIIle Ecole d'été de didactique des mathématiques, Clermont-Ferrand: IREM de Clermont-Fd, 3-46.

CHEVALLARD, Y. Éléments de didactique du développement durable - Leçon 1: Enquête codisciplinaire \& EDD. 2013.

CHEVALLARD, Y. Fundamental concepts in didactics: Perspectives provided by an anthropological approach. In: DOUADY, R.; MERCIER, A. (ed.). Research in Didactique of Mathematics, Selected Papers. Grenoble: La Pensée Sauvage, 1992. p. 131-167.

CHEVALLARD, Y. L'analise des pratiques enseignantes em theórie anthopologique du didactique, recherches em didactiques des mathematiques. Grenoble. La Pensée Sauvage Éditions, 1999. v. 19.2, p. 221-265.

CHEVALLARD, Y. La notion d'ingénierie didactique, un concept à refonder. Questionnement et élémentos de réponses à partir de la TAD. In: MARGOLINAS, C. et al. (org.): En amont et en aval des ingénieries didactiques, XVa École d'Été de Didactique des Mathématiques - Clermont-Ferrand (Puy-de-Dôme). Recherches em Didactique des Mathématiques. Grenoble: La Pensée Sauvage, 2009b. v. 1, p. 81108.

CHEVALLARD, Y. La TAD face au professeur de mathématiques. UMR ADEF, Toulouse, 2009a.

CHEVALLARD, Y. La Transposición Didáctica: del saber sabio al saber enseñado. 2. ed. 3. reimp. Buenos Aires: Aique Grupo Editor, 2005.

CHEVALLARD, Y. Le passage de l'arithmetique a l'algebrique dans l'enseignement des mathematiques au college. Troisième partie. Voies diattaque et problemes didactiques. Petit X, n. 23, p. 5-38, 1989.

CHEVALLARD, Yves. On using the ATD: Some clarifications and comments. Educ. Matem. Pesq., São Paulo, v. 21, n. 4, p. 001-017, 2019. http://dx.doi.org/10.23925/1983-3156.2019v21i4p001-017.

FONSECA, Cecilio; GASCÓN, Josep; LUCAS, Catarina. Desarrollo de un modelo epistemológico de referencia en torno a la modelización funcional. Revista Latinoamericana de Investigación en Matemática Educativa, v. 17, n. 3, p. 289-318, nov. 2014.

FREJD, P. ; BERGSTEN, C. Professional modellers' conceptions of the notion of mathematical modelling - Ideas for education. ZDM Mathematics Education, v. 50 (12), p. 117-127, 2018. https ://doi.org/10.1007/s1185 .

GARCIA, F.; GASCÓN, J.; HIGUERAS, L.; BOSCH, M. Mathematical modelling as a tool for the connection of school mathematics. ZDM Mathematics Education, v. 38, n. 3, p. 226-246, 2006.

GARCIA, Francisco Javier; BARQUERO, Berta; FLORENSA, Ignasi; BOSCH, Marianna. Diseño de tareas en el marco de la Teoría Antropológica de lo Didáctico. AIEM - Avances de Investigación en Educación Matemática - 2019, 15, 75-94. 
JANKVIST, Uffe Thomas e NISS, Mogens (2019). Upper secondary school students' difficulties with mathematical modelling. INTERNATIONAL JOURNAL OF MATHEMATICAL EDUCATION IN SCIENCE AND TECHNOLOGY. https://doi.org/ 10.1080/0020739X.2019.1587530.

JULIE, C. Making relevance in Mathematics teacher education. In: VAKALIS, I.; HUGHES HALLETT, D.; QUINNEY, D.; KOUROUNIOTIS, C. (comp.). Proceedings of 2nd International Conference on the Teaching of Mathematics. New York: Wiley, 2002. CD-ROM.

REVUZ, A. The position of geometry in mathematical education. Educational Studies in Mathematics, v. 4, p. 48-52, 1971.

SCHUKAJLOW, S.; KAISER, G.; STILLMAN, G. Empirical research on teaching and learning of mathematical modelling: a survey on the current state-of-the-art. ZDM - Mathematics Education, v. 50(1-2), p. 5-18,2018. Doi 10.1007/s11858-018-0933-5.

SODRÉ, G. J. M.; GUERRA, R. B. 0 ciclo investigativo de modelagem matemática. Educ. Matem. Pesq., São Paulo, v. 20, n. 3, p. 239-262, 2018. http://dx.doi.org/10.23925/1983-3156.2018v20i3p239-262.

SODRÉ, Gleison De Jesus Marinho, ESPÍRITO SANTO, Adilson Oliveira Do. Modelagem matemática crítica com investigação. VIDYA, v. 33, n. 2, p. 81-91, jul./dez., 2013 - Santa Maria, 2013. ISSN 2176-4603.

SODRÉ, Gleison de Jesus Marinho. MODELAGEM MATEMÁTICA ESCOLAR: uma organização praxeológica complexa. 2019. Tese (Doutorado em Educação em Ciências e Matemáticas) - Instituto de Educação Matemática e Científica, Universidade Federal do Pará, Belém, 2019.

STILLMAN, G. A. (2019). State of the Art on Modelling in Mathematics Education-Lines of Inquiry. In. STILLMAN, G. A. e BROWN, J. P. (eds.), Lines of Inquiry in Mathematical Modelling Research in Education, ICME-13 Monographs, https://doi.org/10.1007/978-3-030-14931-4_1.

WITTGENSTEIN, L. Investigações filosóficas. Tradução: José Carlos Bruni. São Paulo: Editora Nova Cultural, 1999 (Coleção Os Pensadores).

RECEBIDO EM: 22 jun. 2020

CONCLUÍDO EM: 12 nov. 2020 
